Sustainability Assessment Of National Rural Water Supply Program In Tanzania

Word count: $9,134 \quad$ Abstract: yes $\quad$ Keywords: yes

Pages: $\quad 34$

Figures/Captions:07

Tables: $\quad 01$

Electronic artwork: $\quad 0$

MS Type: $\quad$ FLA 


\title{
Sustainability Assessment Of National Rural Water Supply Program In Tanzania
}

\begin{abstract}
$\underline{\text { Abstract }}$
Sustainability of rural water supply programs in developing countries is still an elusive goal. It is widely accepted that as a rule they have failed to deliver benefits to society in the long run. Emphasis has frequently been given on the short-term activities. Fast production of new schemes is thus a common strategy, prioritizing the engineering component, while sidestepping social and participatory issues and community empowerment.

In 2006, the Government of Tanzania launched a national program to meet water sector targets set out in the Millennium Development Goals by the year 2015. In this study we evaluate key features of the program on a sustained basis. There is evidence that the Government is promoting more sustained facilities, focusing on cost recovery and on 'decentralization by devolution'. Nevertheless, there are several shortcomings which threaten the long-term functionality of the infrastructure that has to be built. In light of the implementation of the program, and based on the outputs of its pilot phase, we review the factors that can determine its sustainability.
\end{abstract}

Key words: Africa, Tanzania, rural water supply; sustainability; Millennium Development Goals; learning-based approach. 


\section{Introduction}

In Tanzania, rural drinking water supply came high on the agenda in 1971, when the Party declared that by 1991 all population (both rural and urban) should have access to safe water within easy reach of their homes. The construction of new schemes and their ongoing operation and maintenance was to be a government responsibility. However in the mid 70s, foreign donors started developing water supply programs, largely bypassing government structures. During this decade and the following International Drinking Water Supply and Sanitation Decade in the 1980s, considerable efforts were made to improve water coverage, albeit with negligible long-term effect. Facilities were rapidly built and then transferred to regional water engineers who had neither budget nor capabilities to operate them. These early efforts to provide sustainable water supply and sanitation services thus proved a failure (Therkildsen, 1988; URT, 2002; Kyessi, 2005).

In response to the poor performance of water schemes, the Government introduced a new National Water Policy (NAWAPO) in 1991. Since then, Tanzania has been facing a transition from a socialist economy -based on the principle of 'free water for all'- to a more liberal economy where cost-recovery has become a priority. A revised NAWAPO was launched in 2002 (URT, 2002) as a starting point of a new policy framework, which is to be developed at a national scale. NAWAPO (URT, 2002) is based on (i) the process of 'decentralization by devolution', on (ii) cost-recovery, and on (iii) the issue of ownership. Implementation of these principles has entailed significant implications for agencies of the rural water sector and the way they operate. The Government's new role ('hands off, eyes on') is one of policy and guideline formulation, coordination, monitoring and regulation. The management and coordination of the day-to-day activities moves to the local authorities, which undertake the primary responsibility for implementation of new rural water supply schemes and sanitation infrastructure. Communities are expected to initiate demand for improvements of facilities since it is to be a demand-driven approach, and not only their participation throughout the project cycle has to be guaranteed, but users are also committed to achieve full cost recovery on ongoing operation and maintenance. Finally, while in the past donor interventions often bypassed recipient organizations at national, regional and local level; they are currently required to implement their projects under the supervision of the Government. 
At present, and despite the substantial resources invested to provide safe water and improved sanitation from beginning nineties, the situation shows little improvement. Reducing the existing service coverage gap between rural and urban areas remains a challenge. The last 'Population and Housing Census' carried out in mainland Tanzania (excluding Zanzibar) in 2002 reported that $42 \%$ of rural households and $85 \%$ of urban households have access to improved $^{1}$ water supply (see Figure 1). Moreover, according to the revised NAWAPO (URT, 2002), at least $30 \%$ of all water schemes are not functioning properly. Based on recent researches carried out at local scale, which reach similar outcomes (WaterAid - ODI, 2005; Jiménez and Pérez-Foguet, 2008), there are no obvious reasons to predict significant improvements with regard to this prevalent high rate of non-functionality.

Figure 1. (a) Rural and (b) urban percentage of households (at district level) using improved water sources as their main source for drinking water. Source: WaterAid Tz, 2005.

It is within this background that the National Rural Water Supply and Sanitation Program (NRWSSP) has been launched in 2006 to improve the access to sustained and reliable water supply services for the rural population. Main goal of this national program is to achieve, in a twenty-year period, the service targets set by the Government.

This paper presents main findings of a sustainability assessment of the NRWSSP performed during 2007. In the mid 80s, a thorough study (Therkildsen, 1988) was conducted about the intervention of international donors to improve access to safe water for rural population in Tanzania. The long-term functionality of the schemes implemented during the 'free water for all' culture was assessed. The conclusions of the study emphasized a dilemma between faster production of schemes on the one hand, and a slower pace of production but the promotion of more sustained facilities through a participatory approach on the other.

There is evidence in NAWAPO (URT, 2002) that Tanzania has adopted the second approach. Nevertheless, there are several constraints which threaten the long-term sustainability of the rural water supplies that are to be constructed through the NRWSSP. A pilot phase of the

\footnotetext{
${ }^{1}$ Access to improved water supply means that the main source of drinking water is either from a piped supply, protected well or spring, or rainwater collection (Joint Monitoring Programme, 2000).
} 
program started in 2002. Its completion was expected in 2006 although it is still non-closed. Outputs of the pilot phase show that the dilemma confronted by Therkildsen (1988) has not yet been fully overcome. In light of initial implementation stage of the national program, and based on the poor progress achieved within the sector during last decades, this study assesses the rural Tanzanian strategy.

\section{Methodology}

First analysis focuses on key aspects defining the National Rural Water Supply and Sanitation Program (NRWSSP): outputs of its pilot phase, main goal definition, overall strategy and resources allocation. Discussion of four topics is presented in Section 3. Second, in Section 4, an assessment of the NRWSSP based on main sustainability factors identified in the water policy (URT, 2002) is presented.

Information on the program (targets and outputs produced, costs, financial requirements and other related activities) has been generated through a combination of relevant literature review and pertinent field work. It has been obtained from a wide range of national documents, including sector papers, progress reports, unpublished documents from Tanzanian authorities and donors; as well as published reports from these sources. A comprehensive scientific literature review has also been undertaken regarding to sustainability issues of rural water supplies.

Interviews and meetings were held with technical staff from the local authorities and from the Ministry of Water, non-governmental organizations (NGO), multilateral external support agencies, and private sector individuals with some connection to the sector and/or its programs. The research has also involved field visits to various regions in order to obtain first hand information about the progress and the outputs achieved during the pilot phase of the program, focusing on the institutional structures used in providing water and sanitation services to rural communities in the country. 


\section{The National Rural Water Supply and Sanitation Program in Tanzania}

In the year 2000, the United Nations, through the Millennium Development Goals (MDGs), set international targets for reductions in poverty, improvements in health and education, and protection of the environment. In particular, Target 10 of Goal 7 reads: Halve, by 2015, the proportion of people without sustainable access to safe drinking water and basic sanitation (UN, 2000). Since then, Tanzania is on track towards meeting this target, by first defining coherent sector-related policies (NAWAPO, 2002) and then developing a comprehensive program (NRWSSP, 2006) to put policy in a functional framework.

The NRWSSP has thus been developed as an effort to improve the quality of life of the rural population by sustained and equitable access to safe water and sanitation. It is to be implemented under the overall responsibility of the Ministry of Water, according to the principles and strategies of the NAWAPO (URT, 2002). The first draft was issued in September 2004. After consultations among key sector stakeholders, and based on the outputs produced in the pilot phase (three districts were initially selected), it was finally launched in January 2006. The Program objective specifies levels of coverage to be achieved by 2025 , which should lead to $90 \%$ sustained access to water supply amongst the rural population. Nevertheless, its implementation is suffering considerable delays, and the program is still at an initial stage. Not only pilot phase has not been completed, but up to date -two years laterfew districts have started receiving funds and technical support (though they were initially supposed to be actively involved by July 2006, at least having started with capacity building and training).

In any case, the Program is certainly the biggest opportunity to address (at a national scale) issues such as water depletion, water scarcity and prevalence of water-related diseases, among others. It is therefore worthwhile considering an appropriate alternative to effectively tackle the causes of unsustainability, particularly in light of the high non-functionality rate of the water schemes implemented in the past. In this respect, both NAWAPO (URT, 2002) and NRWSSP (URT, 2006) clearly identifies key aspects regarding to sustainability issues, aimed at achieving target set by MDGs through sustained interventions. Nevertheless, sound implementation plan should also need to focus on key cross-cutting issues. The study identifies following aspects to be addressed. To deal with main constraints detected during 
the pilot phase is recommended, mainly financial difficulties at community level to achieve cost-recovery. With regard to achieving established goals, the need to tackle equity at both regional and local scale as a substantive part of program is highlighted. The strategy used should identify gaps in service delivery and address them in a cost-effective way (either by construction of new infrastructure or by rehabilitation of existing schemes); while the adoption of a more participatory learning-based approach to planning and implementation is promoted. Finally, in terms of resources allocation, foreseeing additional assistance to communities after project completion is suggested.

\subsection{The Pilot Phase: The Rural Water Supply and Sanitation Project}

The Ministry of Water launched the Rural Water Supply and Sanitation Project (RWSSP) in 2002 as a pilot phase to enable the elaboration and development of the subsequent NRWSSP (2006). According to the NAWAPO (URT, 2002), key strategic aim was to promote decentralized, district-based implementation, and community managed water supply service delivery to the rural communities. It thus focused on three different components: institutional strengthening, construction of water schemes, and preparation on a consultative basis with relevant stakeholders of the national program.

The project was designed initially to cover 30 villages in three districts (Kilosa, Mpwapwa and Rufiji), followed by nine additional districts (Handeni, Igunga, Iramba, Kiteto, Kondoa, Kongwa, Manyoni, Morogoro Rural and Singida Rural). In brief, it developed water supply systems by employing a variety of technological options. It roughly had to serve about 250 villages and benefit 500,000 people by constructing more than 1,300 waterpoints (WP), see Table 1.

\section{Table 1}

Data of the Rural Water Supply and Sanitation Project

As shown in Table 1, data confirms that the RWSSP (World Bank, 2002) is still far from being completed, and lessons learnt can not thus be conclusive. Nevertheless, the NRWSSP (2006) has already been launched. It is still early to prove whether the approach used will 
tackle sustainability issues, but there are key aspects that should be addressed to prevent waterpoints from breaking down. The major constraint detected is regarding to financial issues at community level. Not all selected villages completed initial contribution (5\% of capital investment cost), and whilst water entities are self-sufficient in terms of being able to carry out day-to-day maintenance operations, revenue collection does not generate sufficient funds for major repairs and replacements costs.

\subsection{The Goal: Improving towards the Millennium Development Goals}

The NRWSSP targets that the percentage of population in rural areas with access to safe water will be $65 \%$ by 2010 (goal set by the National Strategy for Growth and Reduction of Poverty -MKUKUTA-); at least $74 \%$ by mid 2015 (MDGs); and that $90 \%$ of the rural population will have sustained access to water by 2025 (Figure 3). Meeting the final goal will require extending water supply coverage to an additional 38.5 million people.

Figure 3. Access to improved water sources (at district level) in (a) 2004, (b) 2015 and (c) 2025. Source: URT, 2006.

Not only coverage, but also equity has been taken into consideration in order to achieve all these targets, since reducing the existing gap regarding to access to improved water sources within different regions is essential. Thus, on a sustained basis, some procedures are in place to ensure a transparent mechanism for allocation of resources. Since there are many districts with very low service coverage of safe and clean water, and because of the patchy availability of water resources within the country, the grants are to be allocated depending on the number of unserved people in a district and the technology options to be implemented. At district level, nonetheless, since the Government is not required to follow up how the resources are allocated, there is the risk to provide water and sanitation services to more able communities and not address equity issues, achieving the service coverage targets but threatening sustainability. It highlights the need to monitor the progress of the program at all scales, and its impact on equity of services. 


\subsection{The Implementation Strategy}

The first step towards a sustained access to improved water and sanitation services is to consolidate and understand the current situation, by first identifying and then addressing the gaps in service delivery and institutional capacity. Tackling areas of non or under-delivery by increasing the number of waterpoints constructed and deal with the problem of nonfunctionality in other areas are different options with their own cost implications (Owen, 2006). Identifying the most cost-effective of these opportunities in each area is required if the intervention is to be efficient.

The NRWSSP aims to fill the majority of gaps establishing large-scale, capital intensive water schemes, most of them in areas previously un-served or where existing schemes have broken down beyond repair (Figure 2). Whenever possible, nonetheless, there will be many cases where non-functioning waterpoints can be easily brought back into service, and this option should be prioritized. According to the graph, it is the most cost-effective intervention since the resources invested to repair a water facility are significantly lower than the ones required to build new ones. Analyzing the cause of non-functionality should be also desirable, aiming to reduce recidivism and to propose tailor-made solutions accordingly.

Figure 2. Projected new services and Rehabilitation of existing services, in terms of population served and per capita capital cost. Source: URT, 2006.

Moreover, to integrate a participatory learning-based approach as a key step within the strategy used is recommended. In brief, it means to continually build on experience in order to explore more cost-effective and sustainable models of service delivery, where programs evolve and grow, and are not simply designed and implemented. Monitoring and Evaluation is thus crucial not to monitor deviances between what was planned and what was implemented; but to encourage error detection, to learn from errors, and to plan corrective actions on the basis of this experience. Nevertheless, current monitoring does not usually provide information in sufficient depth for action planning to set policy, determine strategies and target finance to achieve established goals for the water and sanitation sector (Shordt et al, 2004).To be effective, this approach requires an information system for continuous monitoring to obtain relevant, timely and concise information. It should be related to the 
program objectives, and therefore a set of functional indicators (providing useful information and easy to measure) should be identified and clearly discussed with all stakeholders.

In this respect, a strength of the NRWSSP (2006) is the development of an ambitious Management Information System and a set of core indicators as the basis of the monitoring data, focused on both institutional strength and performance of the water facility. However, it has not been yet implemented, which is considerably undermining the effectiveness of the monitoring during these first stages of the program. In any case, it should consider the monitoring of not only the ongoing activities during the project implementation but also the quality of the services supplied, as an efficient tool to measure the functionality of the facilities.

To be efficient, this Information System necessitates a gradual implementation (adopting a staged approach), so that the knowledge required to plan is gained simultaneously with the capacity to implement plans. Similarly, the staff has to be encouraged to report 'what they actually see and do', and not 'what they think the management would like to hear', avoiding surface narrative which is not committed to underlying processes. It implies that there is also the need for some institutional reorientation (Therkildsen, 1988), promoting organizations capable:

- for responsive and anticipatory adaptation; which not only do not deny errors, but look on them as the basis of learning, as a source of vital information for making adjustments in plans or in implementing activities to achieve the proposed program outputs,

- to plan in close cooperation with the intended beneficiaries; building on rather than replacing indigenous knowledge, since rural people have a great deal to contribute to programs, and

- to gain knowledge through action, integrating in the same team all the key actors and fostering (i) researchers to work hand-in-hand with operating personnel; (ii) planning to be done by those responsible for implementation; and (iii) managers to spend a substantial amount of time keeping in contact with village reality.

In contrast, the current institutional framework in Tanzania remains inadequate and lacks the ability to adopt a suitable learning-based approach. At a minimum, it should entail flexibility 
in decision-making at both national and local scales, and the development and implementation of a proper bottom-up reporting system, whereby beneficiaries become a reliable source of information to monitor the performance of the schemes. Then, coordination among stakeholders should allow the experience gained and capacities developed during the overall process to be easily shared with other similar programs, being rate of expansion determined by how fast the necessary organizational capacity can be developed.

In terms of effectiveness, efficiency and replicability, a learning-based approach thus requires appropriate monitoring and flexibility in decision-making processes at all levels. It has been traditionally assimilated at small scale by single projects, which has reported significant advantages to improve implementation strategy by (i) detecting gaps between achieved outcomes of the project and expected results, and by (ii) dealing with identified sources of inefficiency. Nevertheless, to upscale the approach is resulting challenging, mainly because of its increasing complexity. It is no longer acceptable to develop water schemes which are simply handed over to beneficiaries, without evaluating the impact produced. The strategy needs to better identify main outcomes of the program and related risk factors that can undermine them. The latter should then be linked with comprehensively defined mitigation alternatives, which are supposed to be adopted in case regular monitoring detects significant deviances.

In short, a holistic and tailored approach to planning, design, construction and ongoing operation is thus recommended. This clearly requires, however, current poor sector coordination among implementation agencies to be addressed and flexibility in decisionmaking processes to be maintained. It should pay close attention to what happens on the ground in order to prompt detect ineffectiveness or inefficiency, and then refine or adjust the program into each particular context.

\subsection{Resources}

Overall investments required for rural water supply services are estimated at US\$ 1,723.25 million, for which Government and/or external funding has been identified. Main funding comes from external donors (roughly 65\%), though the Government (25\%) and NGOs (10\%) 
are also contributing to reach required capital investment costs. In this respect, current finances are less than the resource requirements during initial years of the Program, and thus additional funds are needed to be raised.

The Program is endeavored to promote and balance efficiency, equity and sustainability; and it thus covers a wide range of technical, economic, educational, capacity building and policy measures that need to be applied by all sector-related stakeholders. In this respect, the presumption that once a new water supply is constructed and 'handed over' to the user community it can be sustained by community financing of operation and maintenance is over-simplistic (Harvey, 2007). In the recent years, there has been a growing awareness and acceptance of the need to support community-based management systems from an overseeing institution to provide encouragement and motivation, monitoring, participatory planning, capacity building, and specialist technical assistance, which has obviously an associated ongoing cost. Though these institutional costs will vary considerably from location to location, an estimation and appropriate budgetary allocation is essential (Harvey, 2007); thus not only considering system construction, system maintenance and some capacity building, but also system rehabilitation and extension costs, maintenance of the existing institutions, and costs of extension staff to monitor and sustain the existing structures and capacities within the community (Fonseca and Njiru, 2003). There is no clear evidence that previous costs have been properly considered by the Government as an item in current financial plan.

In particular, the Program's budget is made up of three different items (Figure 4), though further US\$ 84.43 million are set aside to face possible contingencies (roughly $5 \%$ of total budget). The major component is related to investment in the water schemes (US\$ 1,559.03 million), while the other two parts receive little interest (District Management Support, US\$ 56.41 million; and Institutional strengthening and development, US\$23.38 million). The former basically includes adequate equipment, office space and transport (mostly related to field staff, essential for the coordination and monitoring of the program); while the latter encompasses stakeholder consultations; project planning and management support; capacity building; private sector support; and local authorities strengthening. At first sight, these last two items seem to be underinvested receiving only a small fraction of resources, and to follow up how these resources are allocated within districts thus remains crucial to ensure at least that capacity building is promoted and institutional support is enhanced. Finally, it is 
assumed that on a sustained basis both communities and districts contribute additional $5 \%$ of capital investment costs during the entire time period considered.

Figure 4. Summary of Investment Requirements, in US\$ millions and partial percentage. Source: URT, 2006.

According to Figure 5a, capital investments requirements vary dramatically within different regions mainly because of the existing gap in current coverage levels (Figure 5b). In brief, where capital costs are high is due to low initial levels of coverage and larger total population; since per capita capital investments (based on the total number of beneficiaries) are more homogeneous throughout the country (Figure 5d). In this respect, data analysis has shown that regional variation in per capita investment is dependent on the specific technological solution to be implemented; being handpumps (either in shallow wells or in boreholes) the most used option by beneficiaries. It can also be seen from the graph below (Figure 5c) that not only single community systems (both gravity-flow and pumped) requires higher investment than multiple systems, but that per capita capital costs do not strictly depend on the availability of water source (ground or surface). In this respect, needless to say that in some cases higher initial capital investments can be somehow offset by ongoing operation and maintenance costs.

Figure 5. (a) Total Projected Capital Costs (at district level) in rural water systems; (b) Rural population (at district level) to be served through the NRWSSP; (c) Projected Number of Rural Facilities Installed; (d) Per capita (total beneficiaries) Projected Capital Costs (at district level) in rural water systems. Source: URT, 2006.

\section{Assessing sustainability}

In essence, "sustaining" means to ensure that existing and future investments in the water sector consider the development of appropriate models of waterpoint management. Nevertheless, the drive behind attempts to achieve the MDGs is drawing attention towards increased coverage to meet the national targets and fast production of new schemes, which can potentially divert attention from the need for getting beneficiaries involved, institutional 
capacity building and ongoing maintenance of water facilities, both of them being critical for sustained service provision.

It is much easier, faster and controllable to construct schemes than it is to build up recipient capacity to maintain them. Nevertheless, the NRWSSP should focus on processes rather than on targets. The key appears to be to identify what enables a water scheme to remain operational over a long period of time. In practice, to keep a waterpoint functioning depends on a complex mix of managerial, environmental, social, financial, and technical issues and the capabilities of the institutions and infrastructure designed to support the community (Harvey and Reed, 2004; Mukherjee and Wijk, 2002; Sugden, 2003; WELL, 1998).

Figure 6. Factors affecting sustainability

In particular, the NAWAPO (2002) identifies seven interrelated components, in a way in which sustainability depends on all of them, and that a weakness in any of them can lead to the failure of the scheme. To assist in the pursuit of sustainability, and based on these seven requisites which the Program should not only consider but put into practice, we make the following recommendations:

\subsection{Management at the lowest appropriate level}

The poor performance of centrally managed rural water supply programs implemented in the past caused shift towards a more user-centred approach to development, based on popular participation. Neo-liberal polices of the 1990s further shifted attention from participation to local governance (Khanal, 2003). The underlying theory is that meaningful and rapid development is possible only if it is planned and implemented from below by the people expected to be the beneficiaries of such development, and development from below is best achieved through decentralization (Maro, 1990). It is based on the devolution of responsibility for water schemes from governments to villagers, and on a participatory approach involving users, planners and policymakers at all levels. The process is seen as key to ensuring local participation, representation of felt needs, the equitable distribution of resources, and sustainability. There is evidence that it can only be achieved through a range 
of institutional arrangements. Nevertheless, decentralization to the 'lowest appropriate level' is usually interpreted as the need for local communities to assume responsibility for their water supply (Cleaver, 2004), while little attention has been given to define responsibilities of sector-related institutions, nor to methods for tracking their performance. In any case, the challenge is not the technical considerations relating to water schemes but how to ensure that systems are adequately managed and thus remain functional once installed. At least, it should entail users paying for water services and those payments being appropriately managed and applied to system operation and maintenance.

The NAWAPO (URT, 2002) differentiates between diverse management alternatives (such as a Water User Group (WUG), a Water User Association (WUA), a Board of Trustees, a Cooperative Society and others); aiming to create an entity able to work independently of village government structures. The process of legal registration of these new entities, nonetheless, is complex and challenging; more flexibility and simplicity should be advocated at district and national levels to prevent it from being excessively bureaucratic and ineffective.

At the same time, community water entities as the smallest management unit are the most economically powerful, and there is the need to be monitored as they grow into their roles, to ensure that community contributions are being collected and administered properly. There is also an issue of scale with regard to the population that these bodies should cover, and Cleaver and Toner (2006) emphasize the dilemma between representative bodies on the one hand and efficient management on the other. In this respect, water entities performing at village or larger scale (WUAs) instead of at waterpoint level (WUGs) appears to be more appropriate, and they should thus be strenghtened.

As a management alternative to be considered, the private sector participation model is receiving growing attention in rural areas. Nevertheless, it is currently under-developed, since up to date water supply has been the Government's domain. It clearly lacks skills and experience to satisfactory deliver public services, and instead of overestimating its commitment, capacity building should be prioritized. Moreover, the services and the goods supplied should be affordable to the community, and contracts between beneficiaries and service providers should be fair and equitable. Current capacity of water entities to negotiate 
with private operators is nonetheless very limited, which often results in contradictory contracts that give significantly more benefits to the operators than to the consumers. In any case, Carter et al (1999) states that if the private operation is to be considered, the priority is to develop the industries which can support the sector (as providers of equipments, materials, and services). The key aspect is that reasonable profits should be achievable, while consumers retain appropriate rights, protection, and real choice. Clearly, the Government should promote the rapid implementation of all these proposals through the provision of clear rules and the implementation of appropriate regulatory frameworks (Lee, 2003; Mehta et al, 2005).

The second challenge lies within district departments themselves, particularly the District Water Department. It is committed to assume the leadership during the project implementation. It entails among others the sufficient ability (i) to manage the (limited) resources, (ii) to effectively implement water facilities, (iii) to mediate (if required) in conflict over sources between communities, (iv) to foster a demand-driven and participatory approach to involve the beneficiaries, as well as (v) to following up and monitoring the performance of the schemes to guarantee its functionality once the project is completed. Clearly, not all the districts are equally prepared to efficiently fulfill their responsibilities and they generally lack strategic oversight. Thus, greater emphasis should be placed on building up capacities of the recipient organizations, and on institutional support from the Government and non-Governmental organizations. At present, not only capacity building is receiving a small fraction of the interest and resources allocated through the program, but also mechanisms and priorities to properly administer these resources need to be clearly defined.

Last but not least, the radical change of approach from direct implementation of projects to the enabling of communities to manage their own schemes requires major shifts in the Government's attitude. It tends to be bureaucratic and rigid in their structures, staffing, rules, and procedures (Carter et al, 1999), and new features such as transparency, partnership, flexibility, and empathy should be fostered as emerging hallmarks. New models of institutional, contractual, and legal relationships between communities and government departments should be envisaged. 


\subsection{Communities owning and managing their water schemes}

According to Katz and Sara (1998), the existence of a formal community organization that operates the system affects the overall sustainability of a water system, showing that it is significantly lower in communities that lacked such organizations. Nevertheless, there is a strong need to distinguish between 'community participation' and 'community management', since perceptions of what these terms mean vary greatly (Figure 7). The former is a consultative process designed to establish communities as effective decision-making entities. The latter is a bottom-up development approach whereby the beneficiaries of the water supply assume full responsibility, authority and control over it (McCommon et al, 1990). Based on the low rural water supply sustainability levels which remain throughout developing countries, community participation has gained widespread acceptance to be a prerequisite for sustainability, i.e. to achieve efficiency, effectiveness, equity and replicability (Narayan, 1995; Katz and Sara, 1998; Gleitsmann 2007). Community management has not (Harvey and Reed, 2007).

Figure 7. Segregated Aspects of 'Participation' and 'Management'. Source: Harvey and Reed, 2007.

The reasons for the breakdown of management systems are numerous. The major one is the misconception that services can be managed autonomously by communities, and that governments need only to promote beneficiaries' involvement and then be side-stepped in the process of service delivery by external support agencies (McCommon et al, 1990; Harvey and Reed, 2007). First, participation is not straightforward, and for it to be authentic requires at least social inclusion and democratic engagement (Gleitsmann 2007). Second, community management or any other alternative of management at the "lowest appropriate level" can only become sustainable with appropriate institutional support (McCommon et al, 1990; Carter et al, 1999; Harvey and Reed, 2007), where governments do not neglect their responsibilities to enable communities to realize this. To this end, a qualified district or regional organization (government agency or NGO) will be needed to ensure the long-term functionality of the schemes and to support the programs which they promote. It is needed both as a source of trained technicians, encouraging and motivating the community, periodically monitoring the service performance, and guaranteeing an efficient and an 
appropriate spare parts supply chain; among others. As mentioned, there is room for improvement in the majority of districts in terms of capacity building and institutional support. Little attention is currently given to which institutions achieve such outcomes. Therefore, a clearer strategy needs to be defined for both implementation stage and after project completion, in which appropriate resources allocation should be thoroughly identified.

Another key limitation is the perception that 'ownership' is a prerequisite for community management and is thus crucial to the success of the project (Cleaver, 2004; Doe and Khan, 2004; Cleaver and Toner, 2006). The sense of ownership (and actual legal ownership) that the village water entities have over their new waterpoints (which NAWAPO promotes) is in direct contrast with the understanding that the villagers used to have in the past. The implementer used to work alone in identifying sites and constructing the schemes, and when they broke down, the villagers did nothing to repair the wells, apparently stating that they belonged to the implementer and not to them. There is a widespread sense that ownership of the water supply facility will lead to a responsibility for its management; though in reality, just because a community owns a facility does not necessarily mean that it will acquire a sense of responsibility for its management, nor does it guarantee a willingness to manage or pay for its operation and maintenance. Therefore, it may be more effective to abandon the desire to achieve community ownership and to develop a sense of responsibility for financing the upkeep of the facility (Harvey and Reed, 2007).

\subsection{Availability of spare parts and know how}

The problem of supplying spare parts in rural areas for water schemes and the availability of technicians has often been highlighted. The simplest solution is to use only (if possible) simple technologies which do not require specialist spare parts and components or trained technicians. Nevertheless, at least more than $40 \%$ of all rural water supply schemes have to rely on hand pump technology in Tanzania (URT, 2007a), and a reliable supply chain is therefore required to be implemented.

In essence, a sustainable spare parts supply has to fulfill the following requirements (Harvey and Reed, 2006): (i) available -required components are in stock or rapidly delivered-; (ii) 
accessible -awareness of where to find spares outlets and their proximity to the community-; (iii) affordable -priced within the means of the community-; and (iv) appropriate -of correct specification and good quality-. In rural areas, spare parts and replacements themselves should be bought and held at district level, and sold at cost price to any water entity. Strength of the Program is that most of equipments and technology have been standardized. As a rule, spare parts are nonetheless not available at local level (Dodoma, Dar and other main capitals are then the only possibilities) and reliable outlets have thus to be established. It would ensure spare parts availability when the need arises, minimizing the time required to repair the scheme and thus improving its effectiveness.

At the same time, training should be lengthened while capacity building fostered in various areas. In terms of sustainability, a great deal rests on the maintenance personnel ability to do their work. Therefore, further training for the more complex breakdowns should be promoted, as well as to establish preventive maintenance schedules (which are currently neglected) and leak detection programs.

The newly created water entities are not only legal owners of the scheme but are also committed to select the most appropriate option to mantain the facility. It highlights once more the necessity to properly develop private sector as a feasible alternative. In any case, whatever management options may be in place, the responsibility for routine operation and maintenance ultimately falls to the contracted manager, whether it is a WUA, WUG, or private operator. Clearly, the Government can not be set aside of this process and it is committed to create an appropriate policy framework.

\subsection{Full cost recovery for operation and maintenance of the scheme}

If services are to remain operational, sustainable financing mechanisms need to consider at least operation and maintenance and longer term rehabilitation needs, since full cost recovery systems (also including planning, design, construction and equipment) are significantly beyond the means of most rural communities. The emphasis must be shifted from paying for maintenance of a facility to paying for the provision of safe, adequate and accessible water (Harvey and Reed, 2004). 
It is widely accepted that community financing strategies thus need to include appropriate mechanisms for revenue collection to contribute towards the cost of running the water supply, as well as measures to sustain willingness to pay within the community (Harvey, 2007). In particular, the NAWAPO (URT, 2002) aims to have full cost recovery on operation and maintenance. It states that communities should manage their own facilities by choosing technologies and setting tariff that is affordable and commensurate with their economic status.

Nevertheless, there is no consensus on whether users should pay for capital costs and if so, what percentage is reasonable and how might it be paid (Fonseca and Njiru, 2003). Some researches (Hoko and Hertle, 2006; Kleemeier, 2000; Mehta et al, 2005; Parry-Jones, 2001; WELL, 1998) conclude that the only true indicator of future performance in revenue collection is the completion of the initial contribution stipulated by the implementer. At the same time, there is also a school of thought (Harvey and Reed, 2004) stating that user financing of implementation costs for improved rural water systems is an unrealistic goal. The water policy (URT, 2002) specifies a contribution, in cash and kind, of 5\% of the total capital cost. It can be seen as an indicator to measure the community's willingness to pay. It is also a contradiction in terms of equity since all communities appear to be homogeneous in government policy. First, whilst the Government recognizes water as a basic right, it lays out no specific means for addressing the needs of the poorest communities (Cleaver and Toner, 2006). Second, forced communal labor will doubtfully enhance community ownership (Cleaver and Toner, 2006). Therefore, amendments to the policy should be advocated if the targeted contribution is unrealistic or a big burden for the sustainability of the project. More efforts are required to promote unskilled labor and to introduce effective and reasonable financial regulation of village water schemes.

Equally important, user fees to achieve cost recovery can be a big burden for the most vulnerable groups within the community. They will be forced (in case of unaffordable expenses) to collect water from unprotected sources -when available- or to make do with minimum amounts at other times. Therefore, debate round the financing of water services for the poor could be characterized in terms of a trade-off between equity, cost and sustainability - how can water be made accessible, at an affordable cost, on a sustainable basis (Jaglin 
2002; Cleaver et al, 2005). Since equity at the local level is an essential sustainability criteria, innovative strategies are needed to adequately serve the poorest, either through some form of subsidies (by the Government or by the communities) or through some form of free tariff. A realistic, targeted, and transparent financial mechanism for assisting the poor is required, while ensuring that sufficient finances are generated to sustain services. At present, NAWAPO (URT, 2002) pays little attention to communal and political processes of resource allocation around water.

In any case, and even if an efficient revenue collection is in place, determination of the real costs of service provision is one of the key problems in developing sustainable financing strategies (Fonseca and Njiru, 2003; Mehta et al, 2005), which may result in WUGs collecting insufficient funds to run the facility. In fact, current models of water fund management are sustainable in the short-term (when the waterpoint will not need significant amounts of funds or skills to keep in action). However, they are not proving effective for major equipment replacement, since the more significant problems of sustainability come about when major scheme components break down, usually the diesel engines. In this respect, the policy stipulates that technical assistance and reliable information should be given to water entities regarding to resources needed to maintain the facility, though as a rule they are lacking this institutional support at these first stages of the program. Main aims of costing operation and maintenance are (i) to ensure that communities are aware of ongoing costs and the financial commitment required to sustain their water systems, (ii) to allow them to select the most appropriate technology and system for them, and (iii) to determine the level of external financial support that may be required (Harvey, 2007).

\subsection{The protection of water sources}

The inexorable increase in population and use of water for economic purposes puts ever greater pressure on water resources, and its protection from depletion, pollution and degradation has thus become a priority in Tanzania.

Environmental and water resources management issues emerge to ensure sustainable sources for the water supply systems, since to access safe water entails at least a sustainable water 
source of sufficient quantity and quality. Integrated Water Resources Management implies the integration in a sustainable way of the needs of all users while maintaining a healthy environment. It thus aims to involve all actors: individuals, communities, companies, organizations and governments; in all sectors: irrigation, domestic water supply, industry; at all scales: local, national, and international (Smet and Wijk, 2002). The differentiation of roles and responsibilities according to sector and scale is crucial if it is to be sustainable.

At a national level, better cooperation between key stakeholders should be encouraged, taking into account that while rural water supply services are committed to district authorities, water resources management is to be a basin authorities' responsibility. Likewise, an appropriate monitoring framework needs to be implemented to ensure that the information needed to make decisions at each level and to prepare realistic basin management plans is available. Aimed at improving previous weaknesses, the Government launched in 2006 the Water Resources Management Program. Similar to NRWSSP, it is based on the NAWAPO (URT, 2002), though it was developed to focus on sustainable water resources management and environmental protection. The former is required to ensure sustainable water sources for water supply systems, while the latter is the basis to prevent watershed runoff and groundwater recharge declining.

Within the basins, water resources management has to be considered to guarantee long-term security of supplies (e.g. shallow wells), as there is significant water stress in some areas in terms of both quality and quantity. Similarly, more research should be done in order to better protect the aquifers, particularly into issues such as soil erosion.

At a local level, although communities' involvement in allocation decisions is desired, the goal is to obtain an optimal use of resources, ensuring that local activities do not adversely affect the quality or quantity of water available to downstream users. Catchment's management and source protection, while ensuring an efficient water use (discouraging wasteful use) are thus essential activities to enhance the sustainability of the supply. At the same time, because of patchy availability of water resources, communities are often in conflict over sources. Local authorities should be capable to mediate if required, which highlights once more that not only technical training is required but also capacity building on social issues. 
4.6 Balancing between technology, service level and the capacity of the beneficiaries

The NAWAPO (URT, 2002) establishes the targets for the minimum service level in rural areas. It is required a water point serving no more than 250 people with water of acceptable quality, at a distance of not more than 400 meters from their homestead, and at the rate of 25 liters per person per day. Nevertheless, in some cases achieving these targets requires a huge investment of resources (e.g. sparsely populated rural areas demand a high density of new sources). In others, a water source may be rejected because of unpleasant but not harmful, aesthetic water quality parameters such as color, taste and odor (Carter et al, 1996). Both can have serious consequences and reduce the sustainability of the project. The former because either consumption will not reach the target level, or significant amounts of time and energy will still be spent on water collection (source proximity to home closer than 400 meters is a remote scenario for many rural households in Tanzania). The latter, since the choice of the use of water from alternative sources (mainly surface sources such as streams, rivers and dams) can be linked to the perceived quality of the water, creating potentials for waterborne diseases (Carter et al, 1996). Therefore, the policy needs to be revised to better reflect the reality in the rural context, promoting other levels of service both more realistic and more sustainable.

Likewise, with regard to water quality, awareness of and provisions for water quality monitoring must be strengthened to ensure safe water supply, not only at waterpoint but at household level. A study carried out in Same District (Jiménez and Pérez-Foguet, 2008) shows a significant difference between the number of functional waterpoints and those which additionally provide bacteriological safe water, since $42 \%$ provided water with some kind of coliform. Similarly, and even if the quality of water at source is safe, it often deteriorates before final consumption (during both transport and storage), undermining the main goal of the project.

Finally, despite increased emphasis on the social aspects of water supply, the selection of the technology still has a major impact regarding to sustainability, especially on ongoing operation and maintenance needs. In this respect, involving water entities in the choice of service level and the selection of a water supply system is recommended. It should be both technologically appropriate to their physical and social environment, and financially 
affordable both in the investment phase and during the operation and maintenance phase (Gleitsmann et al, 2007; Harvey and Reed, 2004).

\subsection{The recognition of women as key players and the inclusion of the poor}

It is generally believed that services are better sustained when projects offer informed choices to all potential users (both women and men, poor and better off), thus empowering them to influence the process of service establishment (Gross et al, 2000). However, the assumption made in policy concerning the capacity of communities to manage services to meet goals of equity and sustainability appears to be over-optimistic (House, 2003; Cleaver et al, 2005). To consider gender and poverty is easier to say but much harder to do, and there is still a need for substantial effort, commitment and resources to develop policy and practice aimed at meeting real changes on the ground (House, 2003).

In any case, the consideration of gender and poverty should be a prerequisite linked to project sustainability. In fact, water supply services can perform well technically and be systematically excluding sections of the population (such as the poor). Then, the strategy needs to be amended and some form of targeting the access of most vulnerable groups to safe water should be considered. It is not only to develop an adequate policy framework of entitlements to water. Unless there is external intervention which commit institutions to considering equity in its work, progress on these issues is often reliant on individual staff's commitment. This means equity can be considered or ignored (House, 2003; Cleaver and Toner, 2006). If it is to be promoted, then greater consideration of the inclusive and exclusive effects of local institutions and norms is required. At the same time, the analysis can not only focus on formal organizational solutions, but also on the informal arrangements through which much water access is mediated (Cleaver, 2004).

In Tanzania, the approach used is unlikely to tackle gender and poverty issues. The policy states that to address equitability of service provision is a responsibility of the community. Despite being assisted by external agencies, no clear role for local authorities or the Government has been defined, which considerably hampers their involvement in the process. This raises questions about which organizations are best placed to provide such ongoing 
facilitation: the central Government, a strengthened local government, NGOs, or donor agencies (Cleaver and Toner, 2006). Some research state the role of government in developing the legislative framework to assist local authorities to proactively make such rights real (Schreiner et al., 2004). Cleaver et al (2006) assert that external agencies should play wider roles in facilitating equality of access, beyond merely setting equity criteria. Finally, whilst there is some evidence of success from NGO approaches, limitations are also clear in scaling-up such approaches in order to meet the needs of large numbers of people (House, 2003; Cleaver et al, 2005).

The policy envisages significant benefits of improved water supplies for women, leaving them more time for productive endeavours, adult education and empowerment activities. It could be a simplistic assertion, since the benefits of improved water supplies are likely to impact on different women in very different ways (Cleaver, 2004). It highlights the need to assess gender issues, and since equity is a dynamic concept, monitoring and learning needs to start from the initial contacts with communities and should continue through to the end of the project.

Equally important, pricing can be used to reconcile differing imperatives to make water delivery financially sustainable, such as equity in access, demand management and cost recovery. It is essential that the most vulnerable members within a community are not priced out of the opportunity to access to safe water. In this respect, issues of affordability are vital, though main focus should be on understanding what assists or prevents the poor in first meeting the capital charges of connection, and then the costs of staying connected (Cleaver et al, 2005). The costs of establishing connection can be met through a variety of financial mechanisms, including any form of subsidy, credits (or micro-credits) or loans. There is also the alternative of payment through contribution in kind, either labor or materials. This approach, which NAWAPO (URT, 2002) promotes has been commonly applied, and whilst it has had its successes, it has also been criticized on several grounds (Cleaver et al, 2005). Once access has been established, formal systems require operation and maintenance charges to be met. In particular, NAWAPO (URT, 2002) aims to have full cost-recovery on maintaining the schemes, though little attention is given to how communities should achieve such outcome and guarantee the access of all potential users. Since 'free provision' is not 
considered in Tanzania, the poor should be assisted to meet the charges through coupons or subsidies.

\section{Conclusions}

Therkildsen (1988) conducted in the mid 80s a comprehensive study about the intervention of international donors to improve access to safe water for rural population in Tanzania during the $80 \mathrm{~s}$, when the 'free water' delivery approach was in place. The conclusions of the study emphasized a basic dilemma for policymakers when designing water sector-related policies: Fast production of schemes versus promotion of sustained facilities through a participatory approach. More than 30 years later, the same history repeats itself. The Government has launched a national program to improve the access to sustained and reliable water supply services for the rural population. Based on current implementation schedule, the program is suffering considerable delays, and targets set by MKUKUTA (2010) and MDGs (2015) are unlikely to be achieved.

Nevertheless, the challenge is not only to achieve the national targets by faster production of water supplies, but to ensure that it is done on a sustained basis as a result of local commitments and capacity to plan and implement. In this respect, a number of constraints which threaten the long-term functionality of the schemes have been detected and some recommendations to tackle sustainability are proposed in this work. There is a strong need to identify additional external funding to raise resources needed to implement the program. Local authorities lack strategic oversight to efficiently fulfill their responsibilities, and prior to start receiving funds, technical support to build up capacities is vital. Private sector should be developed to be a reliable management alternative for water entities, and s supportive policy framework is thus needed. In terms of achieving effectiveness and equality in outcomes, the policy of cost-recovery should be revised to ensure that low income households are included in the service delivery. Finally, a proper Management Information System should be in place to monitor deviances between what was planned and what was implemented, and then plan corrective actions on the basis of this experience. 
The Program is certainly the biggest opportunity to address (at a national scale) issues such as water depletion, water scarcity and prevalence of water-related diseases, among others. And there is no room for failure. Today, sustained rural water supplies remain an elusive goal in Tanzania. 


\section{Acknowledgements}

The authors are grateful to all the people who has contributed and provided support for the assessment in various ways. Acknowledgements go to the following: Mr. A. Jiménez (Ingeniería Sin Fronteras - Asociación para el Desarrollo); Mr. Kashililah and Mr. Debwa (WaterAid, Tanzania); Mr. Francis Ato Brown (The World Bank, Tanzania); staff from the Ministry of Water; Mr. Amani Mafuru (District Water Engineer in Mpwapwa); Mr. Charles Bubelwa (Geodata, Tanzania). Further thanks go to two anonymous referees for useful comments and suggestions.

Financial support from the Agencia Catalana de Cooperació al Desenvolupament (Generalitat de Catalunya, Spanish government) and the Centre de Cooperació per al Desenvolupament (Universitat Politècnica de Catalunya) are gratefully acknowledged. 


\section{Appendix}

\section{List of acronyms and abbreviations}

MDGs Millennium Development Goals

MKUKUTA Mkakati wa Kukuza Uchumi na Kuondoa Umaskini Tanzania (NSGRP)

NAWAPO National Water Policy

NRWSSP National Rural Water Supply and Sanitation Program

NSGRP National Strategy for Growth and Reduction of Poverty

RWSSP Rural Water Supply and Sanitation Project

WP Waterpoint

WUA Water User Association

WUG Water User Group 


\section{References}

Carter R. C., Tyrrel S. F., Howsam P., 1996. Strategies for Handpump Water Supply Programmes in Less-Developed Countries. Journal of the Chartered Institution of Water and Environmental Management, 10:130-136.

Carter R. C., Tyrrel S. F., Howsam P., 1999. Impact and Sustainability of Community Water Supply and Sanitation Programmes in developing countries. Journal of the Chartered Institution of Water and Environmental Management, 13:292-296.

Cleaver, F., 2004. From the local to the global: does the micro-level matter in policy making for the Millennium Development Goals? Paper for the conference, The water consensusidentifying the gaps, ESRC Seminar Series, 18-19 November. Bradford Centre for International Development, University of Bradford, (available at www.brad.ac.uk/acad/bcid/seminar/water, last visited June 2008)

Cleaver, F., Franks, T., Boesten, J., Kiire, A., 2005. Water governance and poverty: What works for the poor? Bradford Centre for International Development, University of Bradford.

Cleaver, F., Toner, A., 2006. The evolution of community water governance in Uchira, Tanzania: The implications for equality of access, sustainability and effectiveness. Natural Resources Forum, 30:207-218.

Doe, S.R., Khan, M.S., 2004. The boundaries and limits of community management: lessons from the water sector in Ghana. Community Development Journal, 39(4):360-371.

Fonseca, C., Njiru, C., 2003. Financing and cost recovery: what happens after construction? Proceedings of $29^{\text {th }}$ WEDC International Conference, Abuja, Nigeria, 22-26 September. Water, Engineering and Development Centre, Loughborough University, UK.

Gleitsmann, B.A., Kroma, M.M., Steenhuis, T., 2007. Analysis of a rural water supply project in three communities in Mali: Participation and sustainability. Natural Resources Forum, 31:142-150.

Gross, B., Mukherjee, N., Wijk, C, 2000. Linking Sustainability with Demand, Gender and Poverty: A study in community-managed water supply projects in 15 countries. IRC and The World Bank - Water and Sanitation Program, Washington, DC.

Harvey, P.A., 2007. Cost determination and sustainable financing for rural water services in sub-Saharan Africa, Water Policy, 9:373-391.

Harvey, P., Reed, R. A., 2004. Rural water supply in Africa: Building blocks for handpump sustainability. Water, Engineering and Development Centre, Loughborough University Press, UK.

Harvey, P.A., Reed R.A., 2006. Sustainable supply chains for rural water supplies in Africa. Proceedings of the Institution of Civil Engineers, Engineering Sustainability, 159(1):3139.

Harvey, P.A., Reed R.A., 2007. Community-managed water supplies in Africa: sustainable or dispensable? Community Development Journal, 42(3):365-378.

Hoko, Z., Hertle, J., 2006. An evaluation of the sustainability of rural rehabilitation project in Zimbabwe. Physics and Chemistry of the Earth, 31:699-706.

House, S., 2003. Easier to say, harder to do - gender, equity and water. Paper for Alternative Water Forum, Bradford, 1-2 May. Bradford Centre for International Development, 
University of Bradford, (available at www.bradford.ac.uk/acad/bcid/seminar/alternative_water, last visited June 2008)

Jaglin, S., 2002. The right to water versus cost recovery: Participation, urban water supply and the poor in sub-Saharan Africa. Environment and Urbanisation, 14(1):231-245.

Jiménez, A., Pérez-Foguet, A., 2008. Quality and sustainability aspects in water access indicators: an example from Same District, Tanzania. Proceedings of $33^{\text {rd }}$ WEDC International Conference. Accra, Ghana. Water, Engineering and Development Centre, Loughborough University, UK.

Joint Monitoring Programme, 2000. Global Water Supply and Sanitation Assessment Report 2000. UNICEF/WHO - Joint Monitoring Programme for Water Supply and Sanitation, New York. (available at: http://www.wssinfo.org, last visited April 2008).

Khanal, P.R., 2003. Participation and governance in Local water Management. Paper for Alternative Water Forum, Bradford, 1-2 May. Bradford Centre for International Development, University of Bradford, (available at www.bradford.ac.uk/acad/bcid/seminar/alternative_water, last visited June 2008)

Katz, T., Sara, J., 1998. Making rural water supply sustainable: Recommendations from a global study. UNDP and The World Bank - Water and Sanitation Program, Washington, DC.

Kleemeier, E., 2000. The Impact of Participation on Sustainability: An Analysis of the Malawi Rural Piped Scheme Program. World Development, 28(5):929-944.

Kyessi, A.G., 2005. Community-based urban water management in fringe neighbourhoods: the case of Dar es Salaam, Tanzania . Habitat International, 29(1):1-25.

Lee, T., Floris, V., 2003. Universal access to water and sanitation: Why the private sector must participate? Natural Resources Forum, 27:279-290.

Maro, P.S., 1990. The Impact of Decentralization on Spatial Equity and Rural Development in Tanzania. World Development, 18(5):673-693.

McCommon, C., Warner, D., Yohalem, D., 1990. Community Management of Rural Water Supply and Sanitation Services. UNDP and The World Bank - Water and Sanitation Program, Washington, DC.

Mehta, M., Fugelsnes, T., Virjee, K., 2005. Financing the Millennium Development Goals for Water and Sanitation: What Will it take? Water Resources Development, 21(2):239-252.

Mukherjee, N., Wijk, C., 2002. Sustainability Planning and Monitoring in Community Water Supply and Sanitation: A guide to the methodology for participatory assessment (MPA) for community-driven development programs. The World Bank - Water and Sanitation Program, Washington DC.

Narayan, D., 1995. The contribution of people's participation: evidence from 121 rural water supply projects. The World Bank, Washington, DC.

Ngwenya, B., Kgathi, D., 2006. HIV/AIDS and access to water: a case study of home-based care in Ngamiland, Botswana. Physics and Chemistry of the Earth, 31:669-680.

Owen, M., 2006. Water Supply in Dodoma Region: A status review for WaterAid Tanzania. WaterAid Tanzania, Dar es Salaam, Tanzania.

Parry-Jones, S., Reed, R., Skinner, B., 2001. Sustainable Handpump Projects in Africa: A literature review. Water, Engineering and Development Centre, Loughborough University Press, UK. 
Schreiner, B., Mohapi, N., Van Koppen, B., 2004. Washing away poverty: Water democracy and gendered poverty eradication in South Africa. Natural Resources Forum, 28(3): 171178.

Shordt, K., van Wijk, C., Brikké, F., Hesselbarth, S., 2004. Monitoring Millennium Development Goals for Water and Sanitation: A review of experiences and challenges. IRC International Water and Sanitation Centre, Delft, the Netherlands

Smet, J., Wijk, C., 2002. Small Community Water Supplies: Technology, people and partnership. IRC International and Sanitation Centre, Delft, the Netherlands.

Sugden, S., 2003. Indicators for the water sector: examples from Malawi. WaterAid Malawi, Malawi.

The World Bank, 2002. Project Appraisal Document 22.875-Tz: Rural Water Supply and Sanitation Project, The World Bank, Dar es Salaam, Tanzania.

The World Bank, 2007. Project Appraisal Document 37.385-Tz: Water Sector Support Project. The World Bank, Dar es Salaam, Tanzania.

Therkildsen, O., 1998. Watering White Elephants? Lessons from Donors Funded Planning and Implementation of Rural Water Supplies in Tanzania. Scandinavian Institute of African Studies, Uppsala.

United Nations, 2000. Millennium development goals - United Nations Millennium Declaration, (available at: http://www.un.org/millenniumgoals/index.html; last visited June 2008)

URT, 2002. National Water Policy. Dar es Salaam, United Republic of Tanzania.

URT, 2006. National Rural Water Supply and Sanitation Programme. Dar es Salaam, United Republic of Tanzania.

URT, 2007a. Water Sector Development Programme (2006 - 2025). Dar es Salaam, United Republic of Tanzania.

URT, 2007b. Rural Water Supply and Sanitation Project. Report of the $8^{\text {th }}$ Supervision Mission. Dar es Salaam, United Republic of Tanzania.

WaterAid - Tanzania, 2005. Water and Sanitation in Tanzania: An update based on 2002 Population and Housing Census. WaterAid Tanzania, Dar es Salaam, Tanzania.

WaterAid - ODI, 2005. Learning for Advocacy and Best Practice - WaterAid Water Point Mapping. Report of findings based on country visits to Malawi and Tanzania. Prepared by Katharina Welle, Overseas Development Insitute. (available at: www.wateraid.org/international/what_we_do/policy_and_research, last visited June 2008).

WELL, 1998. DFID Guidance manual on water supply and sanitation programmes. WELL WEDC - Loughborough University, UK. (available at: www.lboro.ac.uk/well, last visited June 2008). 


\section{List of figures}

All figures and tables are prepared to be printed in back/white

(a)

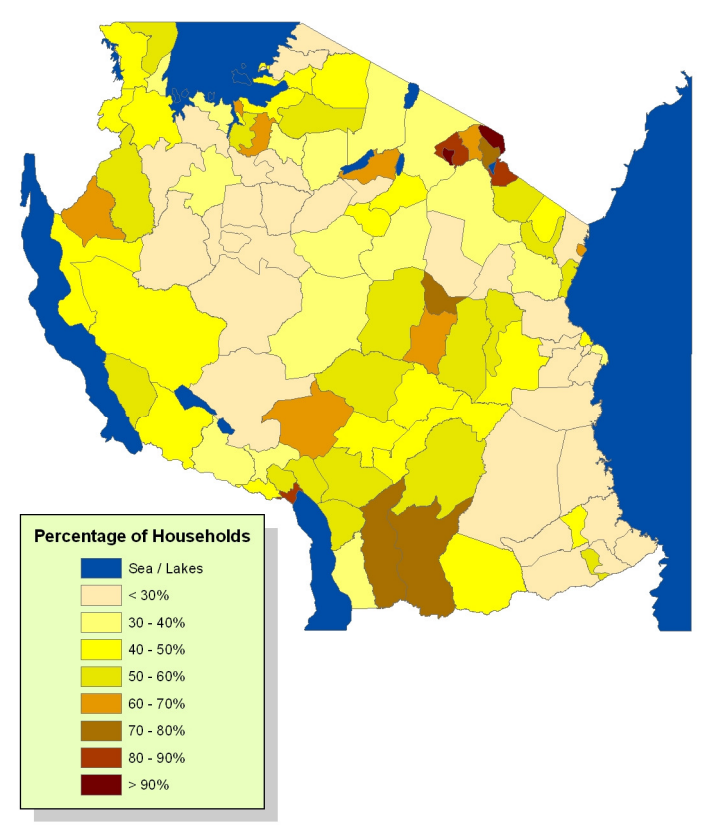

(b)

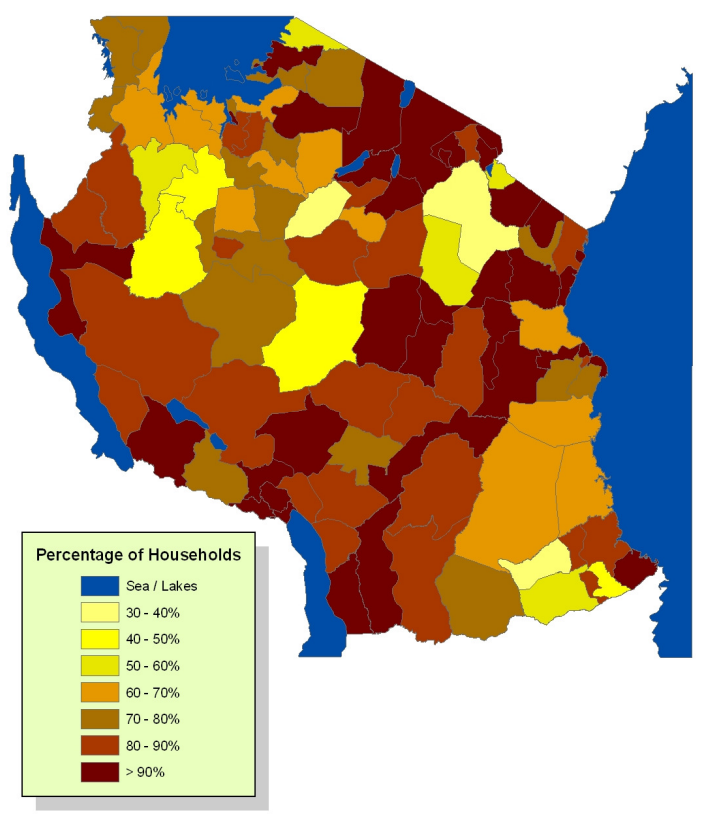

Figure 1. (a) Rural and (b) urban percentage of households (at district level) using improved water sources as their main source for drinking water. Source: WaterAid Tz, 2005.
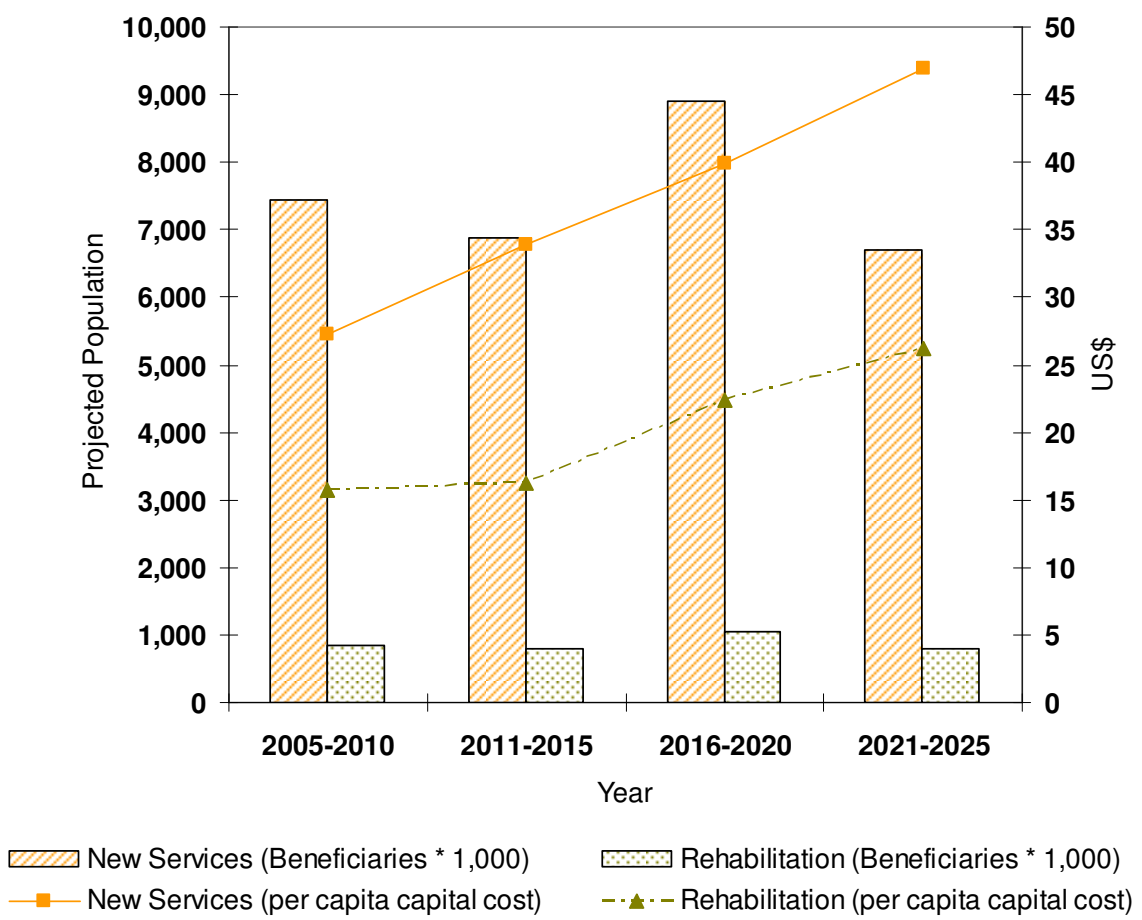

Figure 2. Projected new services and Rehabilitation of existing services, in terms of population served and per capita capital cost. Source: URT, 2006. 
(a)

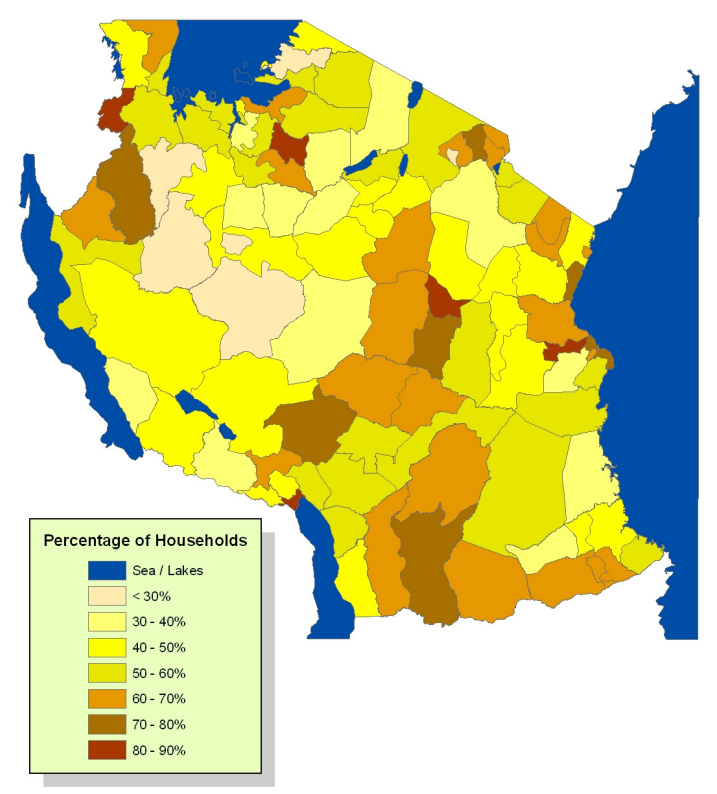

(b)

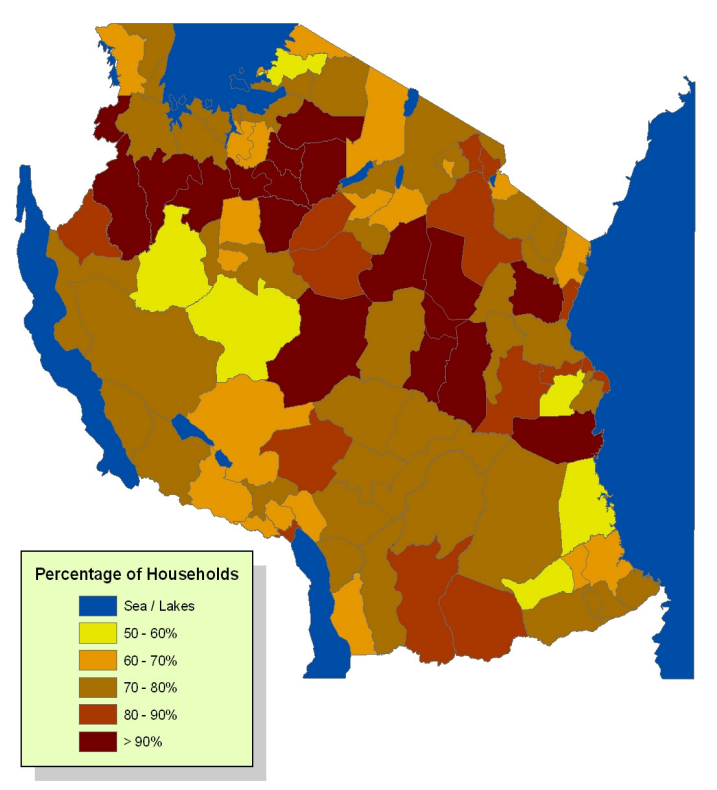

(c)

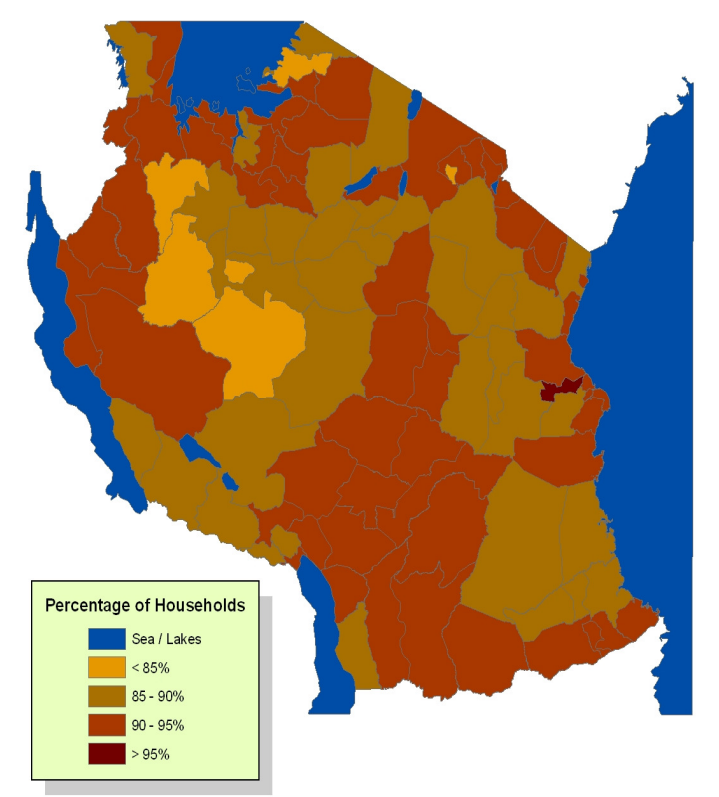

Figure 3. Access to improved water sources (at district level) in (a) 2004, (b) 2015 and (c) 2025. Source: URT, 2006. 


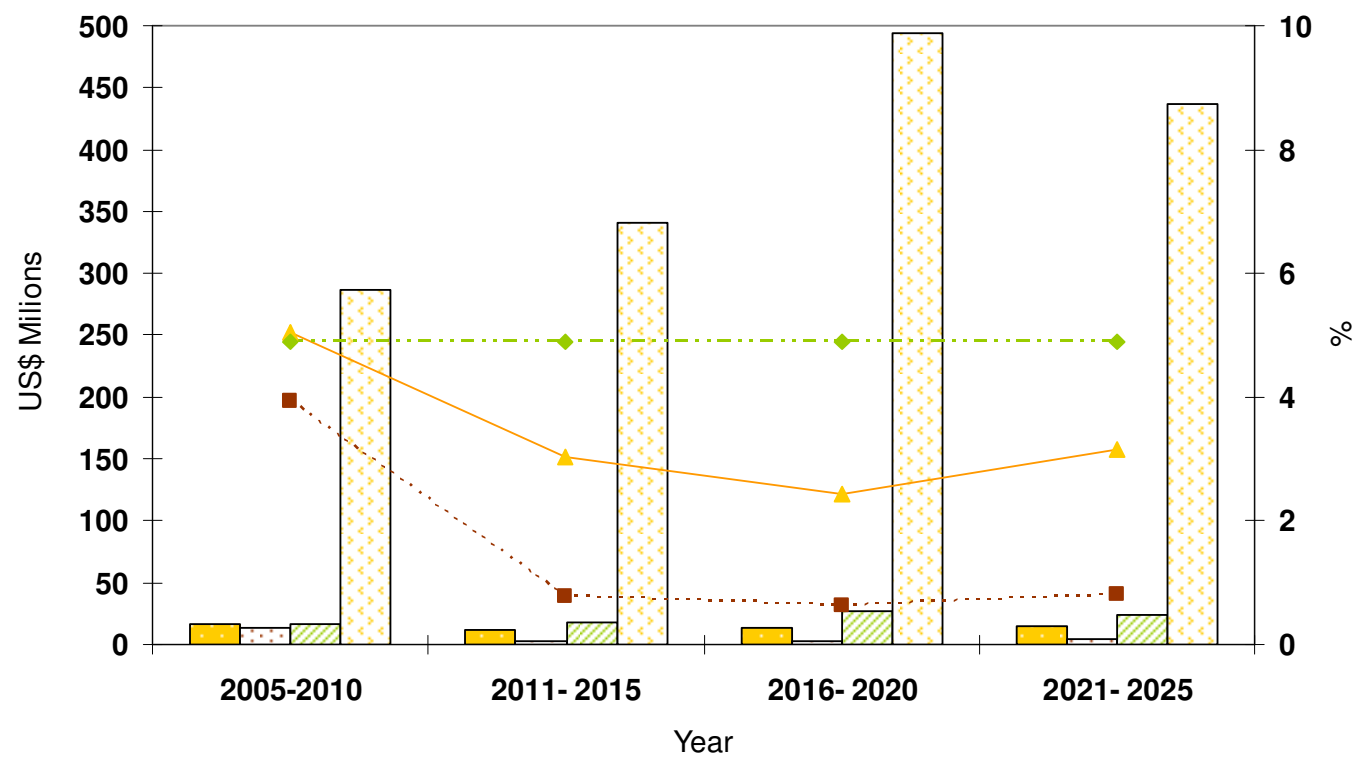

$\square$ District Management $\quad \ldots$ Institutional

Contingency

$\square$ RWS Schemes

__ \% District Management ... . . \% Institutional

$-\cdots \%$ Contingency

Figure 4. Summary of Investment Requirements, in US\$ millions and partial percentage. Source: URT, 2006.

(a)

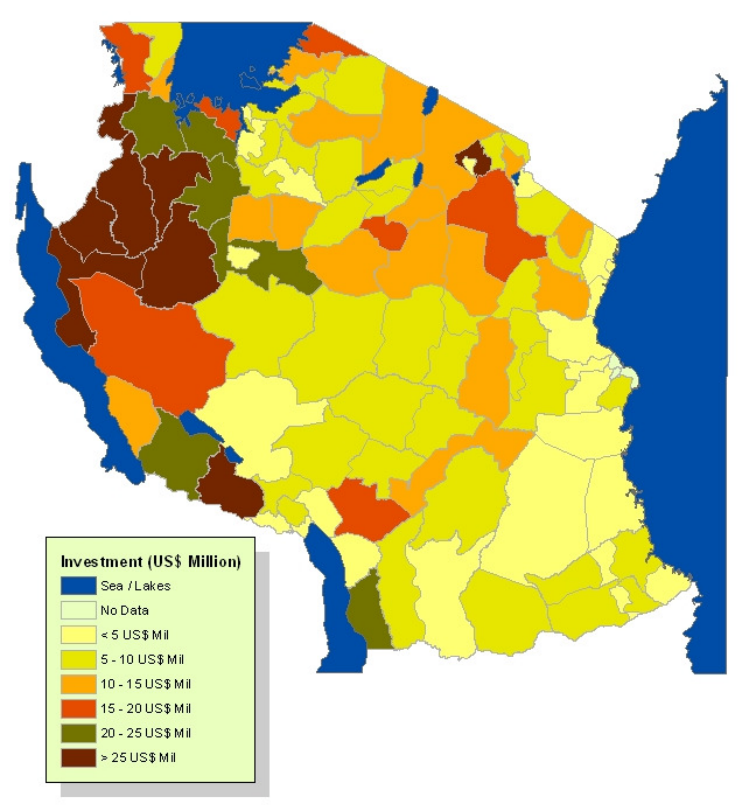

(b)

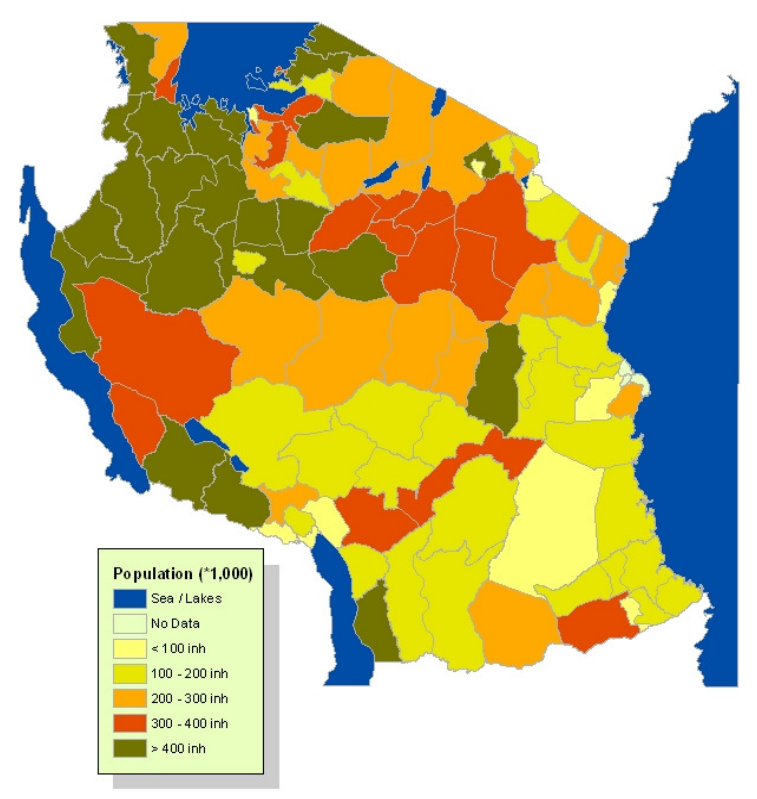


(c)

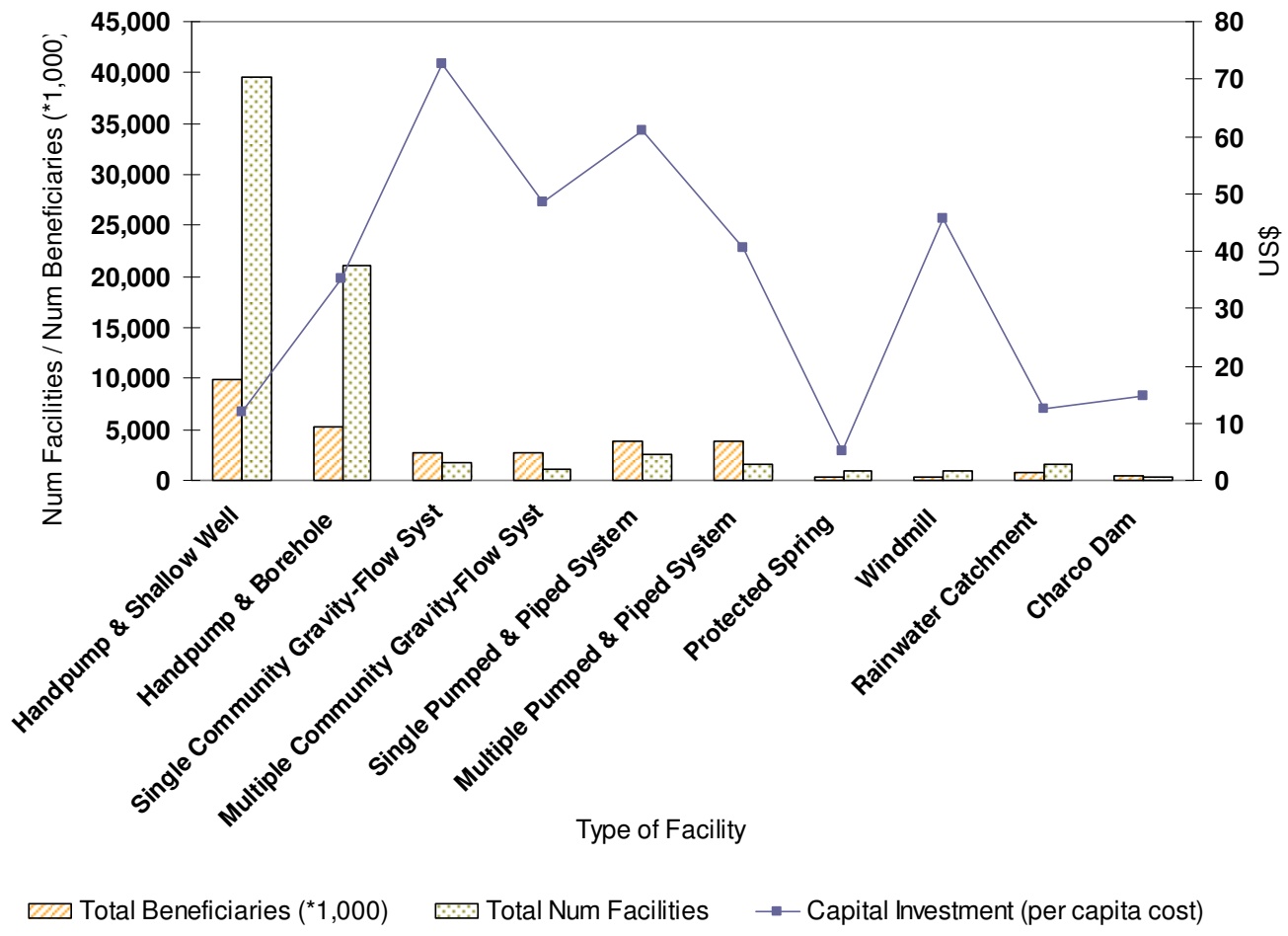

(d)

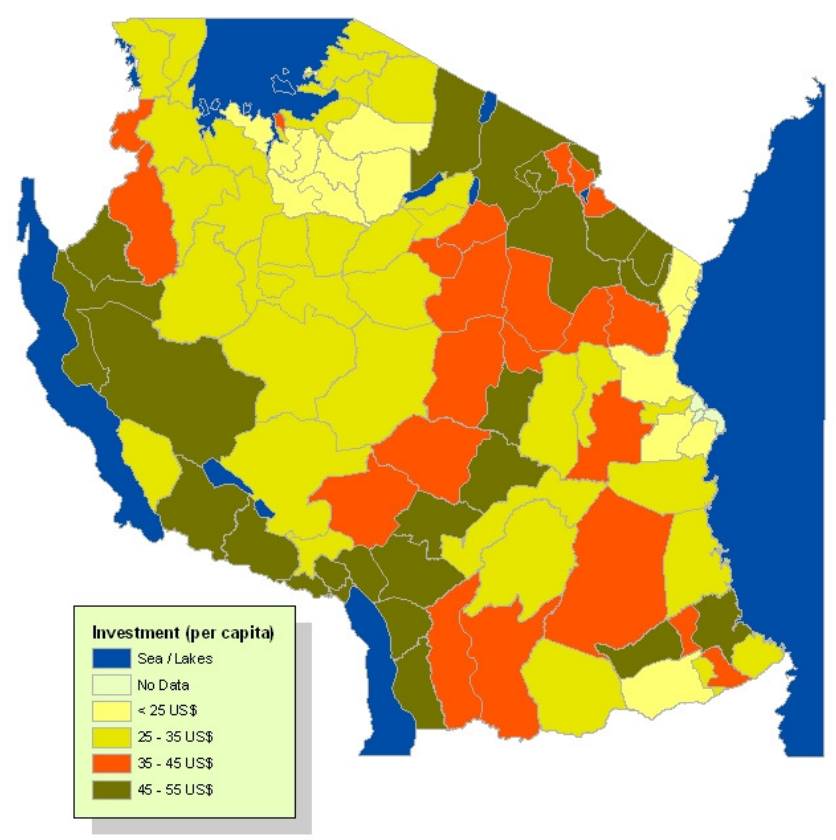

Figure 5. (a) Total Projected Capital Costs (at district level) in rural water systems; (b) Rural population (at district level) to be served through the NRWSSP; (c) Projected Number of Rural Facilities Installed; (d) Per capita (total beneficiaries) Projected Capital Costs (at district level) in rural water systems. Source: URT, 2006. 


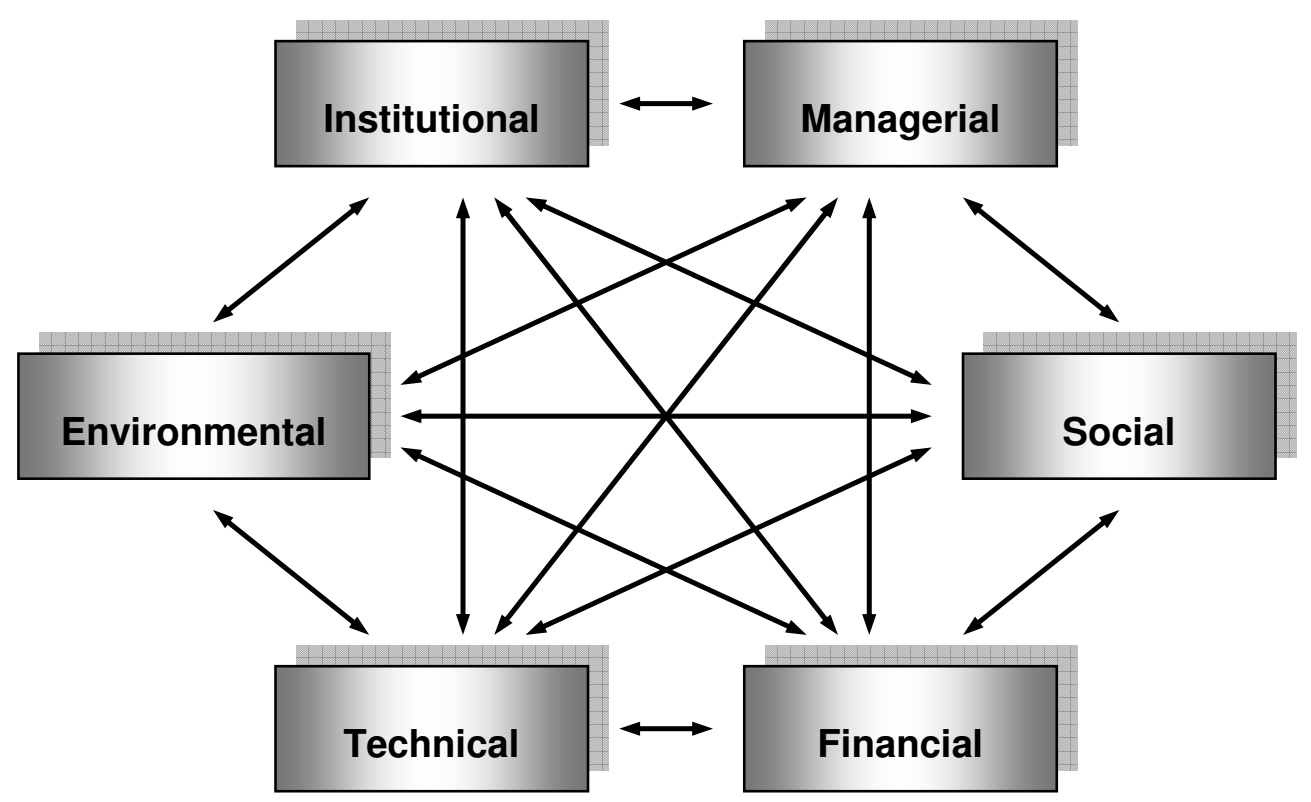

Figure 6. Factors affecting sustainability

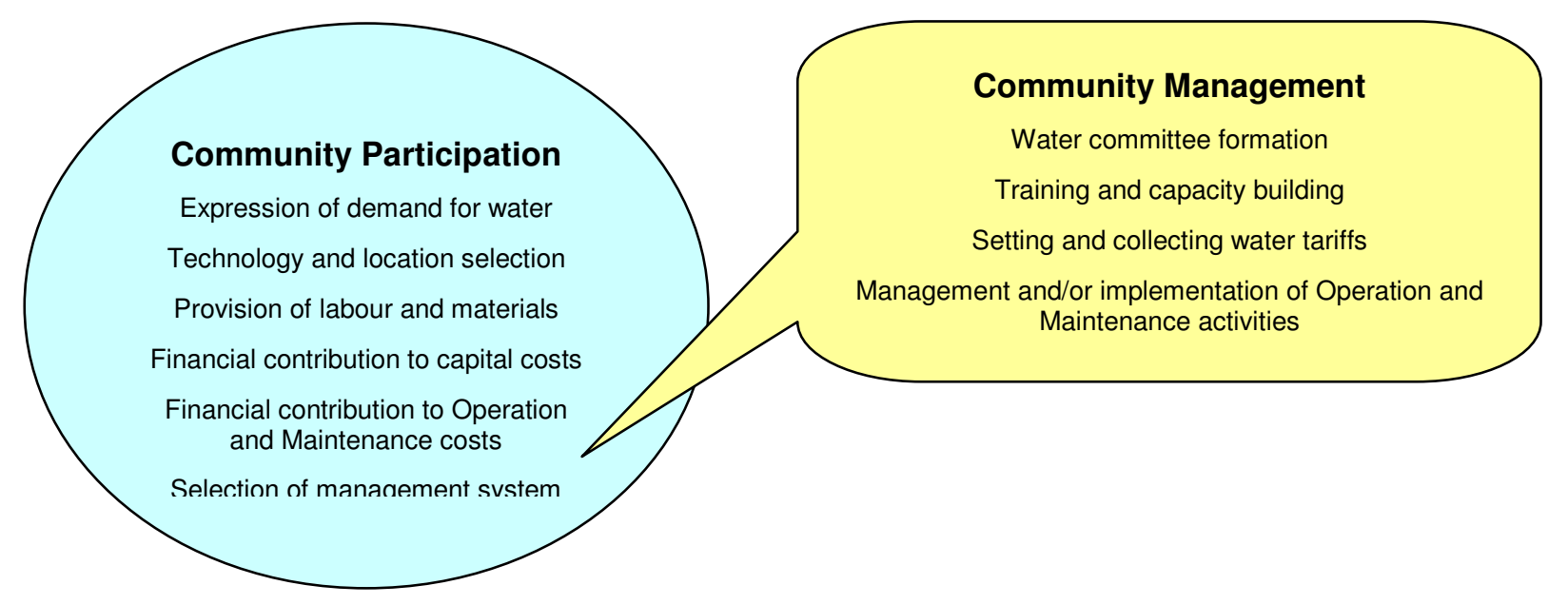

Figure 7. Segregated Aspects of 'Participation' and 'Management'. Source: Harvey and Reed, 2007. 


\section{List of Tables}

\section{Table 1}

Data of the Rural Water Supply and Sanitation Project, RWSSP. Source: Data from the RWSSP: Report of the 8th Supervision Mission, URT, 2007.

\begin{tabular}{|c|c|c|c|c|c|c|c|}
\hline Region & District & $\begin{array}{l}\text { Num of } \\
\text { Villages }\end{array}$ & $\begin{array}{l}\text { Population }^{\mathrm{a}} \\
\text { Census 2000 }\end{array}$ & $\begin{array}{c}\text { Total WPs } \\
\text { Implemented }\end{array}$ & $\begin{array}{l}\text { Total WPs to } \\
\text { be Developed }\end{array}$ & $\begin{array}{l}\text { Population }^{\mathrm{a}} \\
\text { to be Served }\end{array}$ & $\begin{array}{l}\text { Investment }^{\mathbf{b}} \\
\text { US\$ } \$ 1,000\end{array}$ \\
\hline Dodoma & Mpwapwa & 15 & 50.7 & 218 & 0 & 53.1 & 1,375 \\
\hline Dodoma & Kongwa & 10 & 33.2 & 15 & 111 & 31.2 & 1,581 \\
\hline Dodoma & Kondoa & 10 & 28.1 & 0 & 107 & 26 & 506 \\
\hline Manyara & Kiteto & 10 & 24.4 & 0 & 133 & 28.3 & 1,270 \\
\hline Morogoro & Kilosa & 14 & 40.5 & 116 & 92 & 41.1 & 846 \\
\hline Morogoro & Morogoro rural & 10 & 30.8 & 66 & 136 & 50 & 1,042 \\
\hline Pwani & Rufiji & 15 & 47.4 & 153 & 17 & 55.3 & 571 \\
\hline Singida & Manyoni & 10 & 13.2 & 0 & 80 & 20.6 & 1,057 \\
\hline Singida & Singida Rural & 10 & 26.8 & 0 & 132 & 32.7 & 1,805 \\
\hline Singida & Iramba & 10 & 31.3 & 0 & 123 & 30.3 & 1,198 \\
\hline Tabora & Igunga & 11 & 52.2 & 21 & 266 & 70.1 & 1,530 \\
\hline Tanga & Handeni & 10 & 40.0 & 4 & 119 & 30 & 1,581 \\
\hline \multicolumn{2}{|r|}{ Total } & 135 & 418.5 & 593 & 1,316 & 468.7 & 14,360 \\
\hline
\end{tabular}

${ }^{a}$ Population / Beneficiaries x 1,000

${ }^{\mathrm{b}}$ Investment including the hard component (construction of schemes), and excluding the soft component (capacity building) 


\section{Captions}

- Figure 1. (a) Rural and (b) urban percentage of households (at district level) using improved water sources as their main source for drinking water. Source: WaterAid Tz, 2005.

- Figure 2. Projected new services and Rehabilitation of existing services, in terms of population served and per capita capital cost. Source: URT, 2006.

- Figure 3. Access to improved water sources (at district level) in (a) 2004, (b) 2015 and (c) 2025. Source: URT, 2006.

- Figure 4. Summary of Investment Requirements, in US\$ millions and partial percentage. Source: URT, 2006.

- Figure 5. (a) Total Projected Capital Costs (at district level) in rural water systems; (b) Rural population (at district level) to be served through the NRWSSP; (c) Projected Number of Rural Facilities Installed; (d) Per capita (total beneficiaries) Projected Capital Costs (at district level) in rural water systems. Source: URT, 2006.

- $\quad$ Figure 6. Factors affecting sustainability

- Figure 7. Segregated Aspects of 'Participation' and 'Management'. Source: Harvey and Reed, 2007.

- Table 1. Data of the Rural Water Supply and Sanitation Project, RWSSP. Source: Data from the RWSSP: Report of the 8th Supervision Mission, URT, 2007. 